\title{
Oblique Angle Deposition of Columnar Niobium Films for Capacitor Application
}

\author{
M. Tauseef Tanvir, K. Fushimi, Y. Aoki and H. Habazaki* \\ Graduate School of Engineering, Hokkaido University, Sapporo 060-8628, Japan
}

Niobium films with isolated columnar morphology have been prepared by oblique angle magnetron sputtering for capacitor application. Anodizing of the deposited niobium to form dielectric niobium oxide reduces the surface roughness, since the gaps between the neighboring columns are filled with the oxide due to large Pilling-Bedworth ratio for $\mathrm{Nb} / \mathrm{Nb}_{2} \mathrm{O}_{5}$. To increase the gaps between neighboring columns, the influences of the angle of niobium flux to substrate and substrate surface roughness on the columnar morphology of the deposited films have been investigated using scanning electron microscopy and the electrochemical measurements. The deposition on the textured rough substrate surface and at higher angle of the niobium flux from normal to the substrate surface fabricates the niobium films with higher surface roughness. [doi:10.2320/matertrans.MRA2007313]

(Received December 10, 2007; Accepted February 22, 2008; Published April 9, 2008)

Keywords: magnetron sputtering, oblique angle deposition, textured substrate surface, capacitor electrode, dielectric materials, anodic oxide

\section{Introduction}

Barrier-type anodic oxide films on valve metals, including aluminum and tantalum, are of practical importance as dielectric oxides for capacitors in microelectronics industry, as well as of scientific interest originating from the fact that amorphous anodic oxides grow due to simultaneous migration of cations outwards and anions inwards in a cooperative manner. ${ }^{1)}$ Currently, tantalum capacitor, with anodic tantalum oxide employed as a dielectric oxide, is widely used, particularly in small portable electronic devices. However, the limitation of natural resources of tantalum is stimulating the development of alternative capacitor materials. The promising materials are titanium and niobium, since they form oxides with relatively high permittivities, $\varepsilon_{\mathrm{ox}}$, of $\sim 40$, compared with tantalum oxide $\left(\varepsilon_{\mathrm{ox}}=27\right)$. Furthermore, their natural resources are relatively high. However, the performance of anodic films formed on these metals declines due to easy crystallization of the anodic oxides, which causes increased conductivity and enhanced dielectric loss. ${ }^{2-5)}$ It has been recently demonstrated that incorporation of foreign species from metal substrate avoids the degradation of the film properties and even improves the dielectric properties. Examples are niobium supersaturated with silicon, ${ }^{4)}$ nitrogen $^{6,7)}$ and oxygen ${ }^{8,9)}$ and titanium supersaturated with molybdenum, ${ }^{10)}$ silicon, ${ }^{11,12)}$ tungsten ${ }^{13,14)}$ and zirconium. ${ }^{15)}$ Such non-equilibrium alloy thin films were prepared by magnetron sputtering.

To apply these non-equilibrium alloys for capacitors, the surface area of the alloys must be increased since the capacitance, $C_{\mathrm{p}}$, is proportional to the surface area, $S$, as in the following equation;

$$
C_{\mathrm{p}}=\varepsilon_{\mathrm{ox}} \varepsilon_{0} S / d
$$

where, $\varepsilon_{\mathrm{o}}$ is the permittivity of vacuum, $\varepsilon_{\mathrm{ox}}$ the permittivity of the dielectric oxide and $d$ the thickness of the dielectric oxide layer. Current tantalum capacitor uses sintered tantalum powders with open pores to enhance the

*Corresponding author, E-mail: habazaki@eng.hokudai.ac.jp surface area. Such high temperature sintering technique cannot be applied for the developments of porous nonequilibrium alloys.

Here, an attempt to produce porous metallic films by oblique angle deposition (OAD) for capacitor application is presented. The requirements to achieve the controlled porous structure by the OAD technique are self-shadowing effect and limited diffusion of adatoms. ${ }^{16)}$ It has been reported that employing controlled rotation of substrate during OAD is able to produce sculptured thin films; the morphologies of nanopillars, ${ }^{17-22)}$ zigzags, ${ }^{16,23-25)}$ nanospirals ${ }^{26,27)}$ and $\mathrm{Y}$ shape ${ }^{28)}$ have been achieved. The OAD films with controlled microstructures have potential widespread applications, including photonic crystals, sensors, catalyst supports, magnetic storage medias and field emitters. ${ }^{29)}$

In contrast to the extensive studies on the influence of substrate rotation on the thin film morphology in the OAD technique, little attention has been paid to the influence of the substrate roughness on the film morphology. ${ }^{17,30)}$ It is likely that the deposition on a rough substrate produces deposits with enhanced porosity, since shadow regions for flux of depositing atoms should be developed by the substrate (Fig. 1). In the present work, porous niobium films have been deposited by the OAD technique with a particular attention paying to the influence of substrate roughness on the porosity of the deposited films. The porosity has been examined by

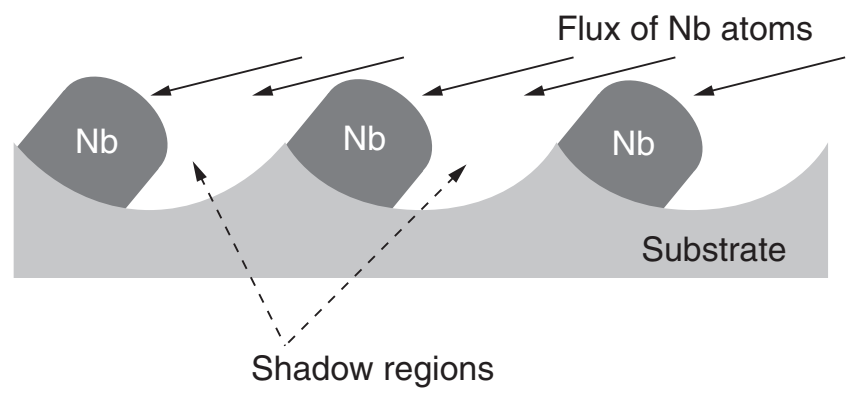

Fig. 1 Schematic illustration of the oblique angle deposition of niobium on rough substrate. 
(a)

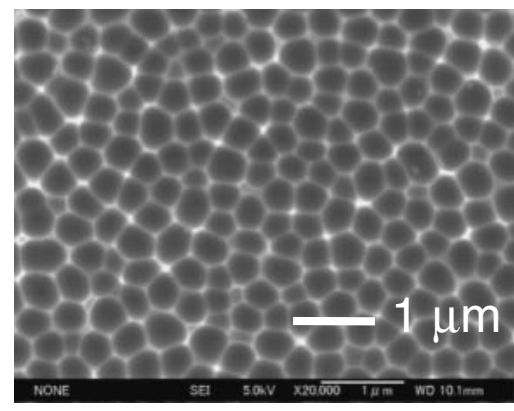

(b)

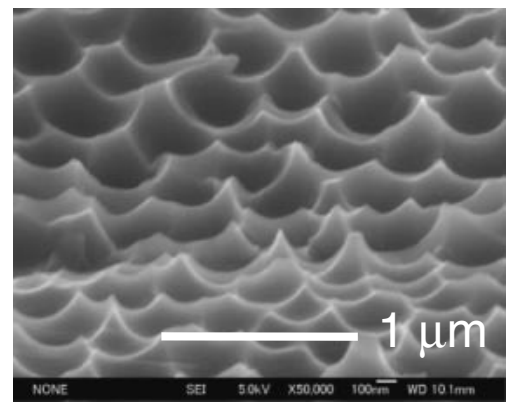

Fig. 2 SEM images of textured aluminum substrate prepared by anodizing at a current density of $50 \mathrm{~A} \mathrm{~m}^{-2}$ in $0.1 \mathrm{~mol} \mathrm{dm}^{-3}$ phosphoric acid for $900 \mathrm{~s}$ and subsequent oxide film removal in a mixture of chromic and phosphoric acid at $353 \mathrm{~K}$.

measuring the capacitance of the oxide film formed by anodizing of the deposits.

\section{Experimental}

Thin films of niobium were sputter deposited for $1.8 \mathrm{ks}$ using $99.9 \%$ niobium target in a high purity argon atmosphere on to the flat glass and rough aluminum sheets. The rough aluminum sheet substrate, shown in Fig. 2, was prepared by anodizing of electropolished aluminum at a current density of $50 \mathrm{~A} \mathrm{~m}^{-2}$ in $0.1 \mathrm{~mol} \mathrm{dm}^{-3}$ phosphoric acid for $900 \mathrm{~s}$, followed by removal of the formed porous oxide film in a mixture of chromic and phosphoric acids at $353 \mathrm{~K}$. The vapor flux incident angles (deposition angles) of $0^{\circ}, 60^{\circ}$, $70^{\circ}$ and $85^{\circ}$, relative to substrate normal, were used under the stationary substrate condition. At $0^{\circ}$ a niobium film with flat surface was produced. The structures of the deposits were identified by grazing incidence X-ray diffraction (incident angle of $\mathrm{X}$-ray $=2^{\circ}$ ) using $\mathrm{Cu} \mathrm{K} \alpha$ radiation. The obtained patterns revealed that all of the deposits had a bcc structure. Surface and cross-sections of the deposits were observed by a JEOL JSM-6500F scanning electron microscope operated at $5 \mathrm{kV}$.

The porosity of the deposited films was first evaluated from the slope of the voltage-time response during anodizing at a constant current density of $10 \mathrm{~A} \mathrm{~m}^{-2}$, relative to the apparent geometrical surface area until $50 \mathrm{~V}$, in $0.1 \mathrm{~mol} \mathrm{dm}^{-3}$ ammonium pentaborate electrolyte at $293 \mathrm{~K}$. Two-electrode cell with a platinum counter electrode was used for the galvanostatic anodizing. Further, potentiostatic anodizing of the deposited films were carried out using a three-electrode cell in the same electrolyte for $900 \mathrm{~s}$ in the potential range between 2 and $10 \mathrm{~V}$ vs $\mathrm{Ag} / \mathrm{AgCl}$. The electrochemical impedance spectroscopy (EIS) was used to evaluate the dielectric properties of the anodic films formed as well as the surface roughness. The EIS data were obtained by applying biased potential $1 \mathrm{~V}$ vs $\mathrm{Ag} / \mathrm{AgCl}$ and $20 \mathrm{mV}$ ac signal amplitude in the frequency range $0.01-10 \mathrm{kHz}$ using Solatron SI 1287 potentiostat/galvanostat and Solatron 1255B frequency response analyzer.

\section{Results and Discussion}

The textured surface of the aluminum substrate with concaves (Fig. 2) was prepared by utilizing porous anodic alumina formation. During anodizing of aluminum in acid electrolytes, such as phosphoric acid used in the present work, self-organized cylindrical pore arrays are developed. Associated with the cell structure of the porous anodic films developed, textured substrate surface is produced, with the center of each concave corresponding to the center of each cylindrical pore of the porous alumina film. The anodic film was removed by immersing the anodized specimen in a mixed solution of chromic acid and phosphoric acid, without changing the surface texture of the substrate. The diameter of concaves obtained is $300-500 \mathrm{~nm}$. Since the formation voltage was $130 \mathrm{~V}$, the size of the concaves is in agreement with the empirical correlation between the formation voltage and cell size of porous films, that is, $2.5-2.8 \mathrm{~nm} \mathrm{~V}^{-1}$. 31,32 )

Scanning electron micrographs of surfaces of the niobium films deposited on flat glass and textured aluminum surfaces at three different incident angles of niobium flux (Fig. 3) disclose the porous nature of the deposited films. The columnar structure of the deposited films is more evident from fractured cross-sections shown in Fig. 4. Finer isolated columns are formed at higher deposition angles on both the flat and textured substrates. At the angle of $85^{\circ}$ a cauliflowerlike surface morphology is developed. Obviously, the gaps between the neighboring columns are enlarged on the textured aluminum substrate, compared with those on the flat substrate. The increased gaps are suitable for capacitor application as explained later. The columns developed are tilted, and the angles of the columns are approximately in agreement with those predicted by computer simulations, as shown in Table 1. ${ }^{33)}$ The thickness of the niobium films markedly decreases with the increased deposition angle (Table 1 and Fig. 4), due to the reduced flux per substrate surface area at the higher deposition angles. The films on the aluminum substrate are apparently thicker compared with those on the flat substrate at each deposition angle (Fig. 4). This may be caused during preparation of fractured surface. During fracturing, the ductile aluminum substrate deformed largely, such that the thickness of the deposited films could not be measured precisely. Even under such situation, it is obvious that deposited column thickness corresponds to the diameter of concaves of the aluminum substrate. In contrast, finer columns are developed initially on the flat glass substrate, with the column size increasing during deposition.

The porosity of the deposited niobium films has been evaluated by galvanostatic anodizing in $0.1 \mathrm{~mol} \mathrm{dm}^{-3} \mathrm{am}-$ monium pentaborate electrolyte, in which film growth proceeds at high current efficiency close to $100 \%$. Figure 5 
(a)

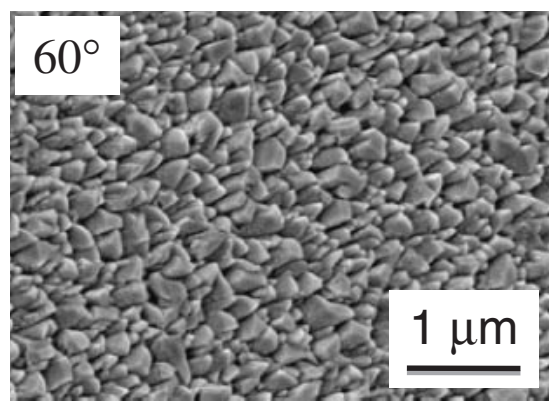

(b)

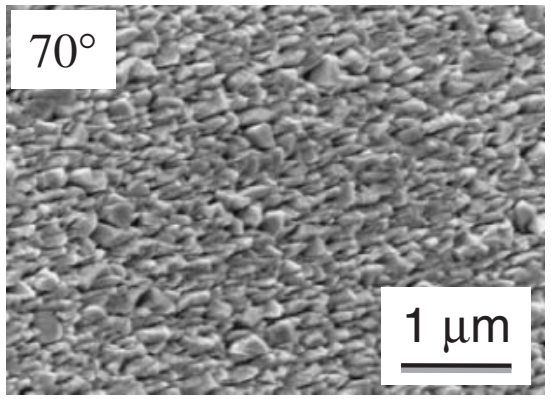

(c)

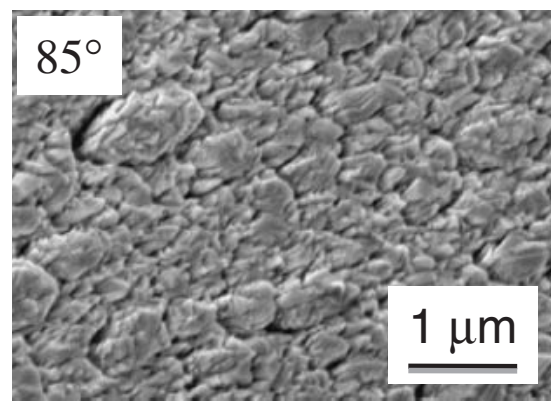

(d)

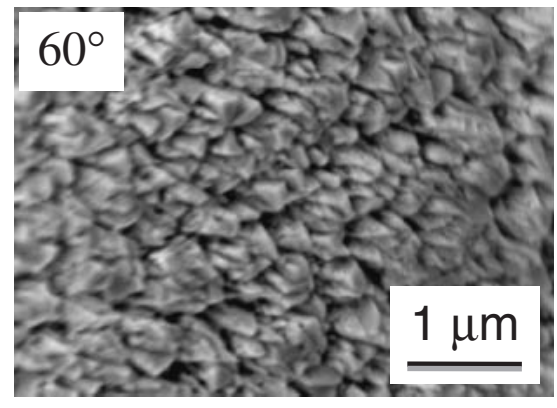

(e)

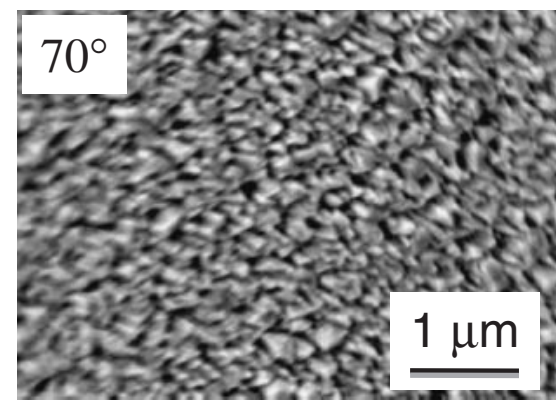

(f)

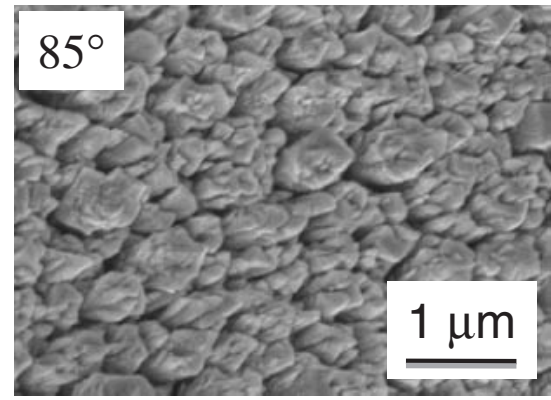

Fig. 3 SEM images of surfaces of the niobium films magnetron sputtered at different deposition angles upon flat glass substrate (a),(b),(c) and textured $\mathrm{Al}$ substrate (d),(e),(f).

shows the voltage-time curves during anodizing at a current density of $10 \mathrm{~A} \mathrm{~m}^{-2}$. The curve of the magnetron sputtered niobium film with flat surface is also shown for comparison. Since the current density is fixed against the apparent geometrical surface area, the increased roughness results in the reduced voltage rise. The linear voltage rise with anodizing time for the niobium with flat surface discloses no change in the surface area during film growth, while increased slope during anodizing of the porous niobium indicates the reduction of the surface area by thickening of the anodic oxide. The reduction of the surface area is caused by the relatively large Pilling-Bedworth ratio (PBR), i.e., the ratio of volume of the oxide formed relative to the niobium metal consumed by anodizing. The PBR for $\mathrm{Nb} / \mathrm{Nb}_{2} \mathrm{O}_{5}$ is reported to be $2.5,{ }^{1)}$ such that small gaps between the individual columns are readily filled with the oxide, reducing the surface area. In agreement with the SEM observations, the niobium films on the textured aluminum substrate reveal the markedly reduced slope compared with the respective films on the flat substrate. The reduction of the initial slope is particularly significant for the films deposited at $60^{\circ}$, due to enhanced shadowing effect on the roughened substrate surface. At the deposition angle of $85^{\circ}$ the initial slopes are similar on both the substrates, but at higher voltages the slope is lower for the film on the textured substrate. In agreement with the surface observations, the gaps between the columns are larger for the films on the textured substrate. The lowest initial slope, that is, the highest surface area, is obtained for the films deposited at 60 and $70^{\circ}$ on the textured aluminum substrate. The higher surface area of these films compared with the film deposited at $85^{\circ}$ may be due to larger film thickness. However, at higher voltages the film deposited at $85^{\circ}$ on the textured aluminum substrate shows the lowest slope, possibly due to widest gaps between columns.

The initial slope of the film deposited at $85^{\circ}$ on flat substrate is as low as that on the textured substrate, but at higher voltages the slope of the former film is even higher than that of the film with flat surface. This can be explained by a schematic model shown in Fig. 6. Due to the high PBR, the narrow gaps between the columns are filled with oxide. After that the further film growth continues only on the top surface region of each column and no film is developed on the oxide-filled gaps. Thus, the apparent surface area is even lower than that of flat niobium film.

Capacitance of the anodic films formed on the porous niobium films at several formation potentials have been examined by electrochemical impedance spectroscopy. During potentiostatic anodic film formation at each potential between 2 and $10 \mathrm{~V}$ vs $\mathrm{Ag} / \mathrm{AgCl}$, the growth of the anodic film followed virtually the high field kinetics; the $\log i$ 
(a)

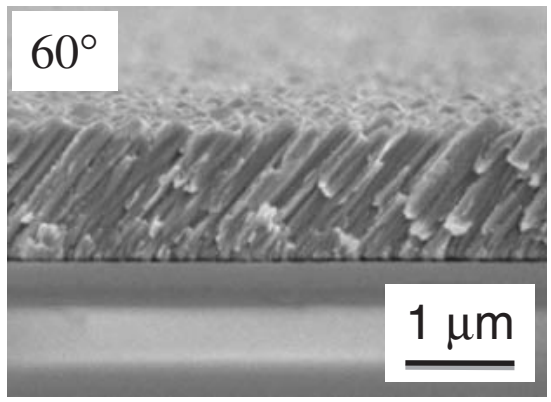

(b)

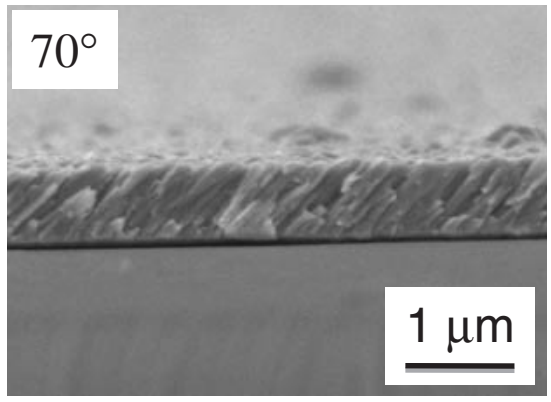

(c)

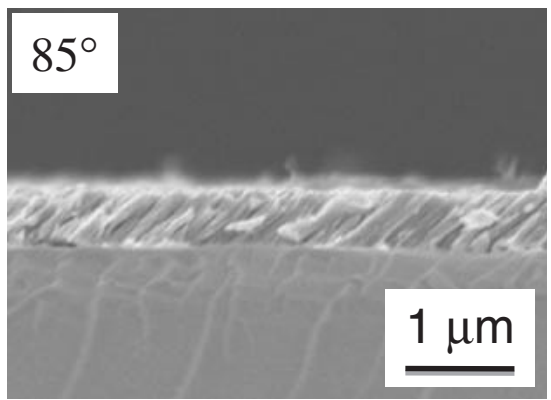

(d)

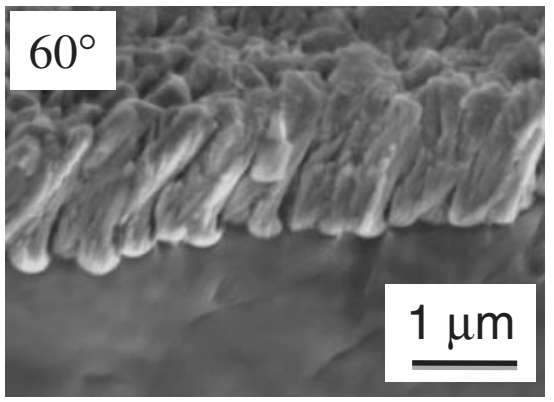

(e)

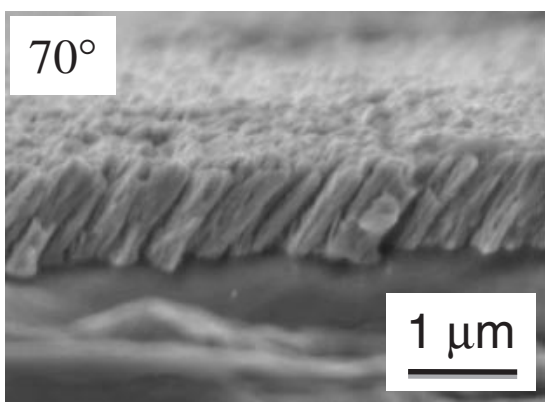

(f)

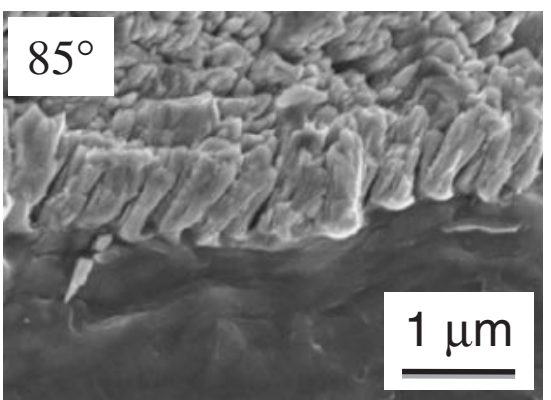

Fig. 4 SEM images of fractured cross-sections of the niobium films magnetron sputtered at different deposition angles upon flat glass substrate (a),(b),(c) and textured Al substrate (d),(e),(f).

Table 1 Experimental and theoretical values of column growth angle $(\beta)$ and film thicknesses of the niobium specimens deposited at three different angles on flat substrate.

\begin{tabular}{cccc}
\hline $\begin{array}{c}\text { Deposition Angle } \\
\text { (deg.) }\end{array}$ & $\begin{array}{c}\beta_{\text {theo }} \\
(\text { deg. })\end{array}$ & $\begin{array}{c}\beta_{\text {exp }} \\
(\text { deg. })\end{array}$ & $\begin{array}{c}\text { Film Thickness } \\
(\mu \mathrm{m})\end{array}$ \\
\hline 60 & 45 & 43 & 1.27 \\
70 & 51 & 47 & 0.67 \\
85 & 58 & 55 & 0.47 \\
\hline
\end{tabular}

decreased linearly with $\log t$ with a slope close to -1 . A typical example of the Bode plots of the anodized porous niobium films is shown in Fig. 7. All the specimens show the almost linear change in the impedance in the wide frequency range with a slope close to -1 . The phase shift is also close to $-90^{\circ}$ in the range of 0.1 to $10 \mathrm{~Hz}$. The behavior is typical of dielectric materials. The impedance shifts to higher values with increasing the formation potential. This is associated with the reduction of capacitance due to thickening of the oxide film. Similar Bode plots were obtained for all specimens examined. As seen in the eq. (1) the reciprocal of capacitance is proportional of film thickness. In addition, the thickness of anodic oxide film changes linearly with the formation potential. Thus, the reciprocal of capacitance of the anodic films formed is plotted as a function of the formation

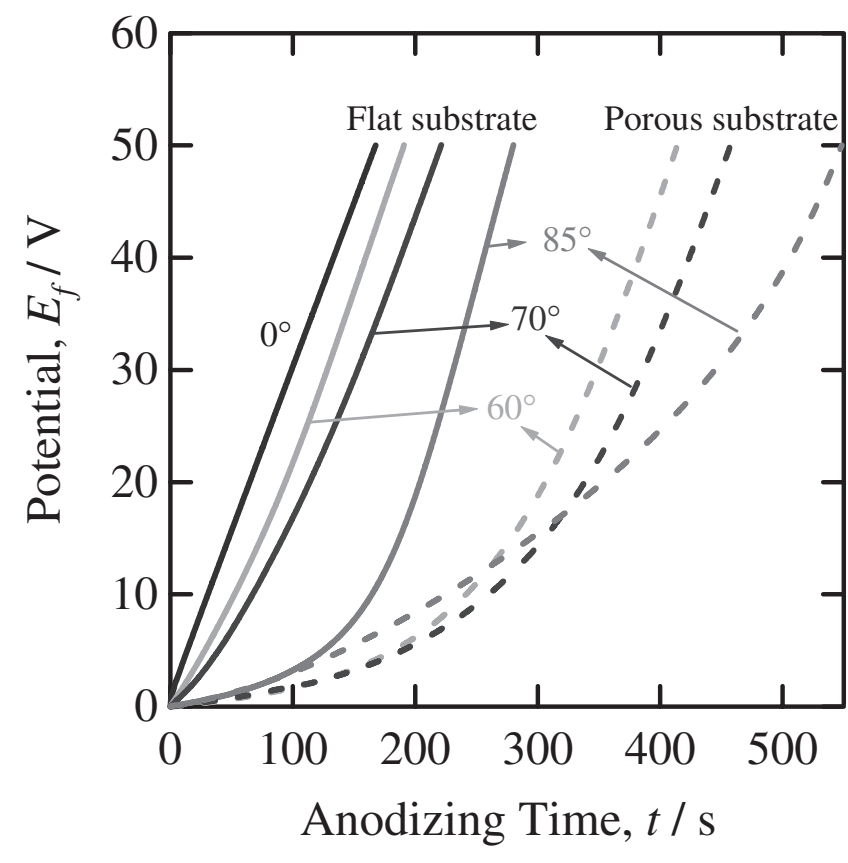

Fig. 5 Voltage-time response of the niobium films magnetron sputtered at different deposition angles upon flat glass and textured aluminum substrates during anodizing to $50 \mathrm{~V}$ at a constant current density of $10 \mathrm{~A} \mathrm{~m}^{-2}$ in $0.1 \mathrm{~mol} \mathrm{dm}^{-3}$ ammonium pentaborate electrolyte at $293 \mathrm{~K}$. 
(a)

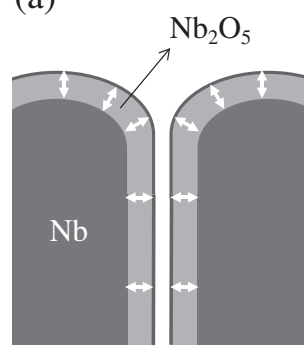

(b)

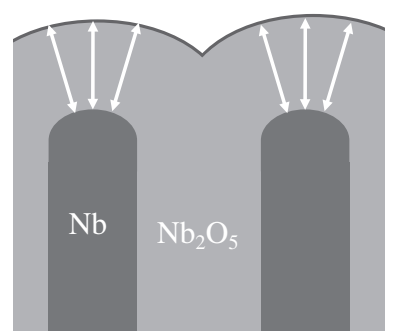

Fig. 6 Schematic diagram illustrating the growth of barrier-type anodic oxide film on isolated columnar metal substrate; (a) before filling a gap between the columns by anodic oxide and (b) after filling the gap, showing limited growth area of anodic oxide.

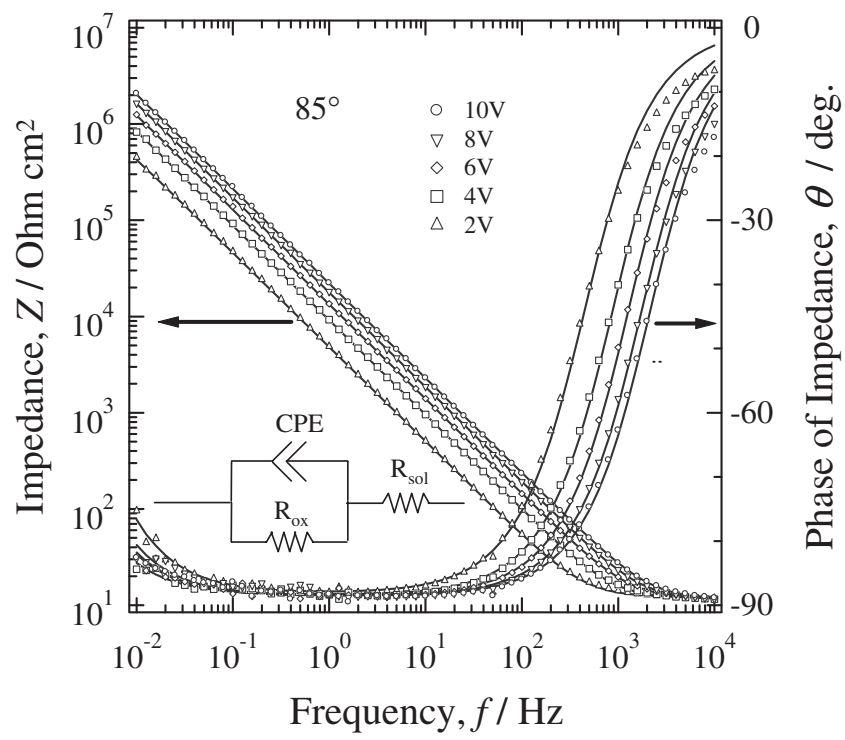

Fig. 7 Bode diagrams of the niobium film magnetron sputtered at a deposition angle of $85^{\circ}$ upon textured aluminum surface after anodizing at several potentials in $0.1 \mathrm{~mol} \mathrm{dm}^{-3}$ ammonium pentaborate electrolyte for $900 \mathrm{~s}$ at $293 \mathrm{~K}$. The diagrams are obtained at the biased potential of $1 \mathrm{~V}$ vs $\mathrm{Ag} / \mathrm{AgCl}$ in the same electrolyte. Lines represented fitting curves obtained from the equivalent circuit shown in the plot.

potential (Fig. 8). As expected, the reciprocal of capacitance of the anodic films formed on the sputter-deposited niobium films with flat surface increases linearly with the formation potential. The extrapolation of the linear line indicates that the oxide film growth commences at $-1.3 \mathrm{~V}$ vs $\mathrm{Ag} / \mathrm{AgCl}$, approximately corresponding to the equilibrium potential for the following reaction.

$$
2 \mathrm{Nb}+5 \mathrm{H}_{2} \mathrm{O} \rightleftarrows 2 \mathrm{Nb}_{2} \mathrm{O}_{5}+10 \mathrm{H}^{+}+10 \mathrm{e}^{-}
$$

For the porous niobium films, the capacitances of the anodic films are higher than that on flat niobium film at each formation potential, due to enhanced surface roughness. The thickness of the anodic films should be independent of the surface roughness at each formation potential, since the film materials formed are always amorphous $\mathrm{Nb}_{2} \mathrm{O}_{5}$ slightly contaminated with boron species from electrolyte and the field strength in the anodic films is controlled by the film material. Thus, the ratio of the capacitance of the anodic film on the porous niobium films to that on the flat niobium film at each

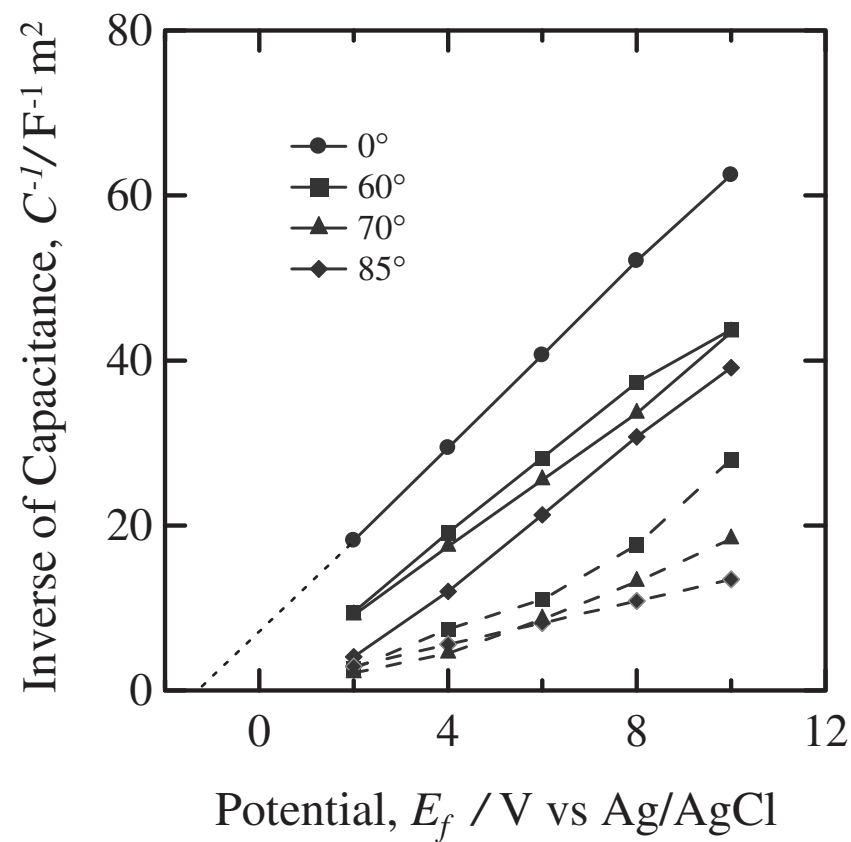

Fig. 8 Change in the inverse capacitances of the anodic films formed on the niobium films, magnetron sputtered at different deposition angles, in $0.1 \mathrm{~mol} \mathrm{dm}^{-3}$ ammonium pentaborate electrolyte with formation potential. Solid lines represented the niobium films on flat glass substrate and broken lines on textured $\mathrm{Al}$ substrate.

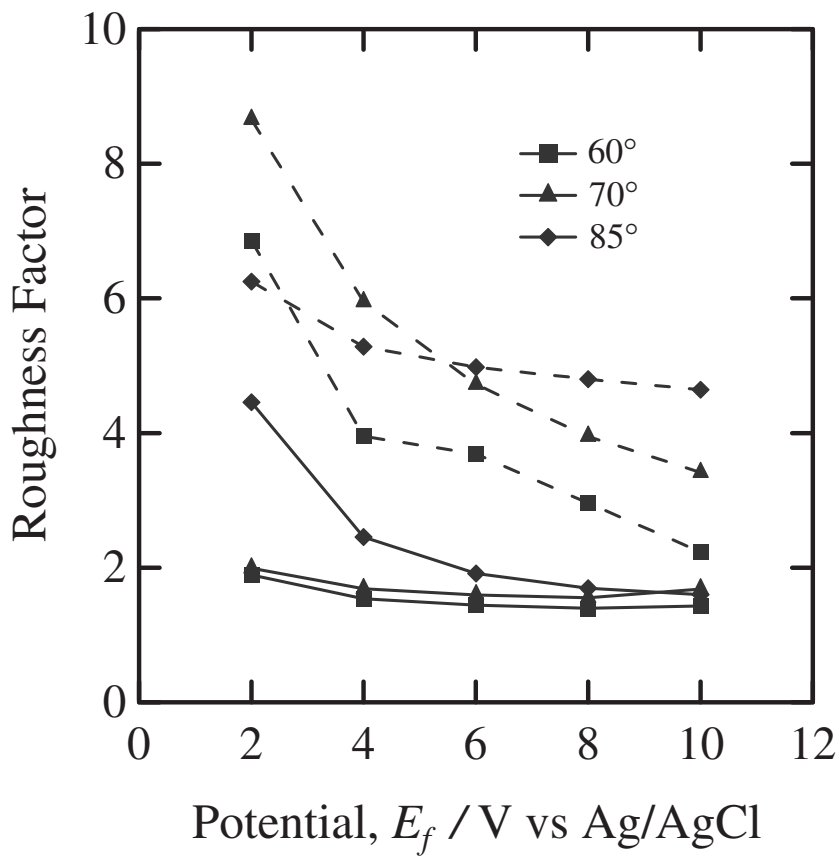

Fig. 9 Roughness factor of the niobium films anodized in $0.1 \mathrm{~mol} \mathrm{dm}^{-3}$ ammonium pentaborate electrolyte at $293 \mathrm{~K}$ as a function of formation potential. Solid lines represented the niobium films on flat glass substrate and broken lines on textured $\mathrm{Al}$ substrate.

formation potential corresponds to the roughness factor.

The change in the roughness factors of the anodized specimens is plotted in Fig. 9. For all the porous niobium films, the roughness factor decreases with the formation potential, in agreement with the change in the slope in the voltage-time response (Fig. 5). For the niobium films 


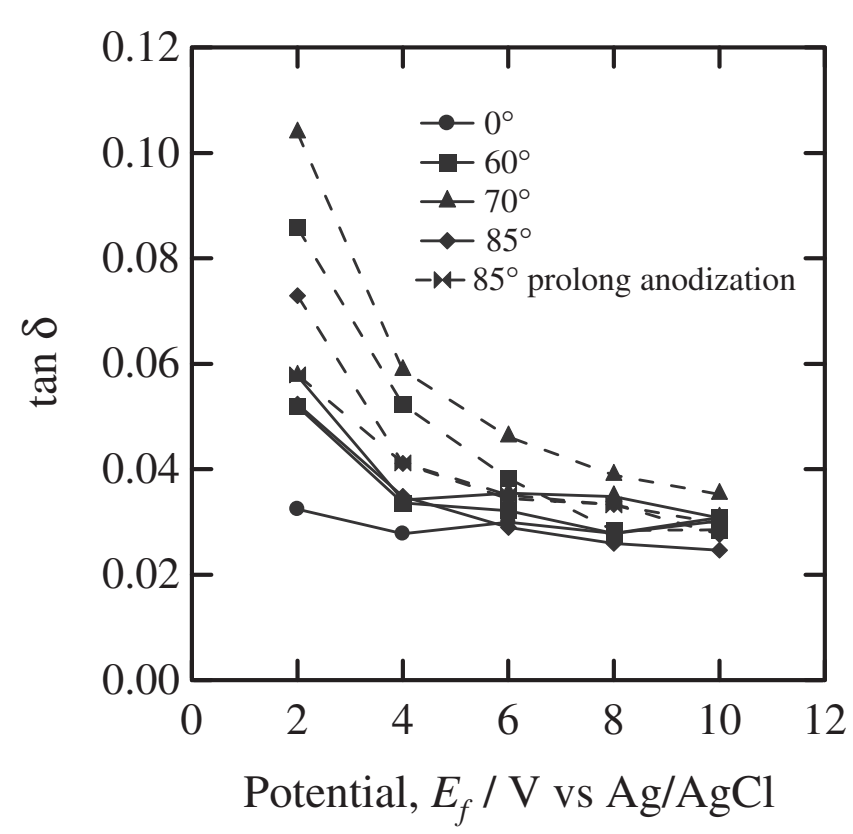

Fig. 10 Dielectric loss of the anodic films formed on the niobium films in $0.1 \mathrm{~mol} \mathrm{dm}^{-3}$ ammonium pentaborate electrolyte at $293 \mathrm{~K}$ as a function of formation potential. Solid lines represented the niobium films on flat glass substrate and broken lines on textured Al substrate.

deposited on the flat substrate, the roughness factor is relatively small and particularly at the deposition angles of 60 and $70^{\circ}$ the factor becomes almost constant irrespective of the formation potential. Relatively high roughness factor is obtained only when the deposition angle is $85^{\circ}$. However, the roughness factor becomes as small as that deposited at 60 and $70^{\circ}$ at high formation potentials, suggesting that the gaps between individual niobium columns are quite narrow and readily filled with the anodic oxide. In contrast, the larger roughness factors are obtained for the niobium films deposited on the textured aluminum substrate. An important fact is that even at low deposition angle of $60^{\circ}$ the surface area is as high as that at the deposition angle of $85^{\circ}$ at the low formation voltages, when the textured aluminum substrate is used. This fact is of practical importance since the deposition of niobium is faster at lower deposition angle. However, at higher formation potentials the niobium film deposited at $85^{\circ}$ shows the largest surface area even for the films deposited on the textured aluminum substrate. One of the possible reasons for the largest surface area for the niobium film deposited on the textured substrate at $85^{\circ}$ is the lowest thickness of the niobium; gaps between the individual columns generally tend to decrease with thickening of deposits. The influence of the deposition time on the film morphology and surface roughness is now in progress and will be reported separately.

Dielectric loss is also an important parameter for capacitor application. Figure 10 shows the dielectric loss at frequency of $10 \mathrm{~Hz}$ as a function of the formation potential. At low formation potentials, the dielectric loss is larger for the specimens deposited on the textured aluminum substrate, but is similar for all the specimens at high formation potentials more than $5 \mathrm{~V}$. Thus, the formation of columnar niobium films with high surface area has minimum influence on the dielectric loss. It was confirmed that the dielectric loss at the low formation potential for the specimens deposited on the textured aluminum substrate was further reduced by prolonged anodizing.

\section{Conclusions}

Through the examination of niobium deposition by magnetron sputtering, it has been demonstrated the high potential of oblique angle deposition technique for preparation of porous columnar films for capacitor application. The utilization of textured substrate surface, prepared by anodizing of aluminum in phosphoric acid and subsequent oxide film dissolution, is particularly effective in producing the porous films with high surface area. On flat substrate the highly porous niobium is deposited only when the deposition angle is as high as $85^{\circ}$. In contrast, porous niobium is deposited even at $60^{\circ}$ on the textured substrate. The surface area decreases with increasing formation potential of the anodic niobium oxide films, due to the large Pilling-Bedworth ratio for the $\mathrm{Nb} / \mathrm{Nb}_{2} \mathrm{O}_{5}$. By depositing niobium at $85^{\circ}$ on the textured substrate, the reduction of the surface area is suppressed.

\section{Acknowledgments}

The present work was supported in part by the Murata Science Foundation.

\section{REFERENCES}

1) J. P. S. Pringle: Electroche. Acta 25 (1980) 1420-1437.

2) A. Aladjem: J. Mater. Sci. 8 (1973) 688-704.

3) H. Habazaki, M. Uozumi, H. Konno, K. Shimizu, P. Skeldon and G. E. Thompson: Corros. Sci. 45 (2003) 2063-2073.

4) H. Habazaki, T. Matsuo, H. Konno, K. Shimizu, S. Nagata, K. Matsumoto, K. Takayama, Y. Oda, P. Skeldon and G. E. Thompson: Electrochim. Acta 48 (2003) 3519-3526.

5) K. Nagahara, M. Sakairi, H. Takahashi, K. Matsumoto, K. Takayama and Y. Oda: Electrochim. Acta 52 (2007) 2134-2145.

6) H. Habazaki, T. Matsuo, H. Konno, K. Shimizu, S. Nagata, K. Takayama, Y. Oda, P. Skeldon and G. E. Thompson: Thin Solid Films 429 (2003) 159-166.

7) H. Habazaki, T. Matsuo, H. Konno, K. Shimizu, K. Matsumoto, K. Takayama, Y. Oda, P. Skeldon and G. E. Thompson: Surf. Interface Anal. 35 (2003) 618-622.

8) H. Habazaki, T. Ogasawara, H. Konno, K. Shimizu, K. Asami, K. Saito, S. Nagata, P. Skeldon and G. E. Thompson: Electrochim. Acta 50 (2005) 5334-5339.

9) H. Habazaki, T. Ogasawara, H. Konno, K. Shimizu, S. Nagata, K. Asami, K. Takayama, P. Skeldon and G. E. Thompson: J. Electrochem. Soc. 153 (2006) B173-B177.

10) H. Habazaki, M. Uozumi, H. Konno, S. Nagata and K. Shimizu: Surf. Coat. Technol. 169 (2003) 151-154.

11) H. Habazaki, K. Shimizu, S. Nagata, P. Skeldon, G. E. Thompson and G. C. Wood: J. Electrochem. Soc. 149 (2002) B70-B74.

12) H. Habazaki, K. Shimizu, S. Nagata, P. Skeldon, G. E. Thompson and G. C. Wood: Corros. Sci. 44 (2002) 1047-1055.

13) H. Habazaki, K. Takahiro, S. Yamaguchi, K. Shimizu, P. Skeldon, G. E. Thompson and G. C. Wood: Phil. Mag. A 78 (1998) 171-187.

14) H. Habazaki, M. Uozumi, H. Konno, K. Shimizu, S. Nagata, K. Takayama, Y. Oda, P. Skeldon and G. E. Thompson: J. Electrochem. Soc. 152 (2005) B263-B270.

15) H. Habazaki, M. Uozumi, H. Konno, K. Shimizu, S. Nagata, K. Asami, K. Matsumoto, K. Takayama, Y. Oda, P. Skeldon and G. E. Thompson: Electrochim. Acta 48 (2003) 3257-3266. 
16) K. Robbie and M. J. Brett: J. Vac. Sci. Technol. A 15 (1997) 14601465.

17) C. M. Zhou and D. Gall: J. Vacuum Sci. Tech. A 25 (2007) 312-318.

18) C. M. Zhou and D. Gall: Thin Solid Films 515 (2006) 1223-1227.

19) M. Malac and R. F. Egerton: J. Vacuum Sci. Tech. A 19 (2001) 158 166.

20) M. Malac, R. F. Egerton, M. J. Brett and B. Dick: J. Vacuum Sci. Tech. B 17 (1999) 2671-2674.

21) K. Robbie, C. Shafai and M. J. Brett: J. Mater. Res. 14 (1999) 3158 3163.

22) B. Dick, M. J. Brett and T. Smy: J. Vacuum Sci. Tech. B 21 (2003) 23-28.

23) M. Suzuki, T. Ito and Y. Taga: Appl. Phys. Lett. 78 (2001) 3968-3970.

24) J. Lintymer, N. Martin, J. M. Chappe, P. Delobelle and J. Takadoum: Surf. Coat. Technol. 180-81 (2004) 26-32.

25) R. Messier, V. C. Venugopal and P. D. Sunal: J. Vacuum Sci. Tech. A
18 (2000) 1538-1545.

26) O. Toader and S. John: Science 292 (2001) 1133-1135.

27) S. R. Kennedy, M. J. Brett, O. Toader and S. John: Nano Letters 2 (2002) 59-62.

28) J. Wang, H. C. Huang, S. V. Kesapragada and D. Gall: Nano Letters 5 (2005) 2505-2508.

29) J. J. Steele and M. J. Brett: J. Mater. Sci. Mater. Electronics 18 (2007) 367-379.

30) M. O. Jensen and M. J. Brett: IEEE Trans. Nanotech. 4 (2005) 269-277.

31) J. P. O'Sullivan and G. C. Wood: Proc. R. Soc. London, A 317 (1970) 511-543.

32) W. Lee, R. Ji, U. Gosele and K. Nielsch: Nature Mater. 5 (2006) 741-747.

33) R. N. Tait, T. Smy and M. J. Brett: Thin Solid Films 226 (1993) 196-201. 